\title{
The use of social technologies in Spanish young people: a global behaviour model in teenagers
}

\author{
Gil-Pechuan Ignacio • Conesa García M. Pilar
}

Published online: 8 February 2013

(C) International Network of Business and Management 2013

\begin{abstract}
The majority of all Spanish youths aged 12-17 use online social networking sites (internet and mobile technology), according to a new local survey of teenagers conducted by Valencia University, Fepad \& the Universidad Politécnica de Valencia. The survey also found that older teens, in particular girls, are more likely to use these sites. For girls, social networking sites are places to reinforce preexisting friendships, while for boys these networks provide opportunities for flirting and making new friends. In both cases, business relations in the future will be influenced by this new relationship method with 'new business relationships' being taken on by 'digital natives' as opposed to the current 'digital immigrants' who have not taken on board this network technology as quickly. The objective of this study is to present our research on the relationship between web 2.0 technologies and the behaviour and personality of the teenagers who form the object of the study as well as the potential dependencies, and resulting personal, academic and family disorders that may stem from abuse of these technologies, especially via mobile phones. The main objective is to explore how web-based technologies lessen or generate different types of disorders in today's society, particularly amongst teenagers.
\end{abstract}

Keywords Social technologies · Behaviour model $\cdot$ Participative social technologies · Web 2.0

\footnotetext{
G.-P. Ignacio $(\bowtie) \cdot$ C. G. M. Pilar

Business Administration Department, Universidad Politecnica de Valencia,

C/Vera s/n, 46022 Valencia, Spain

e-mail: igil@doe.upv.es

C. G. M. Pilar

e-mail: mconesa1@doe.upv.es
} 


\section{Introduction}

We propose that the expansion of technology generates certain non-desirable behaviour (as it is not controllable) to currently take on several differentia characteristics, where new networks are established through technological social networks and also through exposure that did not previously occur on such a massive scale as it does today. Until a relatively short time ago, characteristics such as isolation and withdrawal were considered disorders that could end in those involved taking toxic substances or exhibiting undesirable behaviour. Today, such extreme accessibility deforms behavioural phenomena that can derive in tendencies as they allow teenagers to form groups that may contain homogeneous content generated precisely due to different types of dependence, in many cases, openly and publicly, without being aware of the fact.

The majority of studies on technologies that provide or foment relationships that have been carried out from a social network approach visualize these technologies as a process of communication via which individual attitudes and behaviour are influenced by the social micro structure (Wejnert 2002). Thus, it becomes a process of contagion determined by factors of social cohesion, structural equivalence, popularity, range (access) and spatial proximity from which researchers have created several different models to predict the effects of the structure on changes in attitude amongst people linked by different types of relationship and who occupy certain positions in the aforementioned structure ${ }^{1}$.

\section{Cohesion}

The direct interaction between individuals, especially between members of subgroups of marked emotional ties, explains the adoption processes to a large extent. Cohesion enables the exchange of knowledge by reducing existing competitive and motivational impediments, in particular because this transfer is beneficial for the receiver, but costly for the source. The presence of close links with third parties around a relationship helps to overcome these impediments (Reagans and McEvily 2003).

Moreover, dense subgroups (cliques) contain many of the references preferred by its individual members and generate a sense of belonging that imposes greater pressure on them to conform to an expected behaviour. Owing to both effects (comparison-competition and pressure to conform), the greater the density within a group or subgroup, the greater the influence and similarity to be expected between its members will be. Strong links (homophiles) that characterise cohesive relationships are vital to the internal diffusion of the network (especially for tacit knowledge transfer, which is characteristic of technological innovation) due to its

\footnotetext{
1 See for example: Burt (1978, 2005); Erickson (1988); Friedkin (1984, 1999); Friedkin and Johnssen (1997); Marsden and Friedkin (1994); Michaelson and Contractor (1992); Mizruchi (1993); Obstfeld (2005); Reagans and McEvily (2003); Strang and Soule (1998); Valente (1996, 2005).
} 
relevant role in the processes of influence, comparison and social learning ${ }^{2}$ The most common variables for predicting adoption are thus inversely related to the size of the network and are directly proportional to its density. The frequency of interaction between members also reflects both effects.

\section{Structural equivalence}

For authors such as Burt (1987), competition amongst people of a similar status (i.e. amongst people with similar peer groups and structural position) is the driving force of contagion. Those that possess links with similar types of people tend to behave in similar ways even when there are no direct connections between them. The greater the structural equivalence between the two actors, the greater the similarity expectations between their behaviour. According to Wejnert (2002), structural equivalence is determined by demographic factors (gender, age, race and marital status), social factors (education and occupation) and cultural factors (language, tradition, religion, values and norms).

\section{Range}

Weak and heterophile links (Liu and Duff 1972; Granovetter 1973, 1982; Hansen 1999; Levin and Cross 2004) are fundamental aspects during the early diffusion of new ideas and behaviours because they provide access to other parts of the network which would otherwise remain unconnected as well as links to external and nonredundant sources of information. Burt $(1992,2005)$ in his review of the hypothesis of Granovetter on the 'strength of weak links' suggests that more than in the weakness of the link, the strength of such links lies in the 'bridging' function of these actors who broaden the range of the network and cover the structural gaps in the network, acting as information intermediaries between subgroups. Because of such a role, these intermediaries are usually early adopters of innovation. Moreover, the positional advantage they possess goes to form their 'social capital'.

\section{Popularity}

Prominent, well-connected members of a group (i.e. those close to its centre) are normally opinion leaders, and generally adopt innovations which are consistent with group norms, while resisting the adoption of innovations that do not fit in with these ideas. Conversely, marginal members of the network are less affected by others' judgements and it is more likely that they will be amongst the first to adopt innovations that are not in line with the values and norms of the group (Becker

\footnotetext{
${ }^{2}$ On the effects of the homophile, authors such as McPherson et al. (2001) indicate that diffusion is driven by agents with similar social, organizational and strategic characteristics, given that people perceive that it is simpler and more relevant to learn from those in similar conditions. However, the homophile can operate in the opposite sense, favouring resistance to innovation. Owing to this, other authors point to a certain level of heterophilia (and of weak links) which means that innovation becomes diffused amongst different subgroups. This is a key element in the analysis of the role of opinion leaders (Dagenne and Forsé 1999; Feder and Savastano 2006).
} 
1970; Rogers 2003). This train of thought also explains contagion in non-reciprocal relationships: on one hand, members lower down the pecking order are motivated to take on a new innovation to be more like the leaders; on the other hand, the decision to adopt an innovation by the prestigious members drags others along with them by varying the local patterns of judgement.

\section{Spatial proximity}

Contagion amongst actors who are physically close to one another is one of the most common findings in the literature on diffusion. Geographical proximity enables different types of interaction and processes of influence. Consequently, data on geographical location are normally a powerful tool for predicting diffusion patterns. These models imply that the members of a network are distributed in such a way that in the social space, their physical proximity corresponds to a relational closeness: the closer together two people live, the stronger their links should be, they are more likely to have the same references and role models, and therefore it can be expected that their attitudes and behaviour will be very similar. However, these models are very restrictive because they imply an absence of asymmetries, intransitivity or subgroups in the existing relationships in the network. Nyblom et al. (2003) have put forward a recent application of this type of model.

Beyond these general models, the effects of technology-based networks on innovative behaviour and attitudes can also be predicted by analysing the structure of relations at different levels: nodal (individual), diadic, triadic, subgroup and whole network (Cf. Monge and Contragent 2003).

\section{The individual level}

The actors with the highest levels of centrality (of degree) are normally the opinion leaders. As indicated above, they tend to adopt culturally acceptable innovations earlier than the rest and are opposed to those that are culturally unacceptable (Becker 1970). In a recent analysis on the diverse measurements of centrality and their degree of fit to reflect the flow of different types of elements amongst the actors in a network, Borgatti (2005) indicated that degrees of centrality are a good measure of immediate influence, in other words, of the probability of 'infection' as a function of the number of actors with whom the producer has links. On the other hand, the Eigenvector of geodesical distances is also a good measure of the risk of the contagion node, and it can therefore be used to analyse processes of 'influence'. The difference between both measures is that the degree of centrality does not consider long-term indirect effects.

\section{The diadic level}

At this level, attitudes and similarity in behaviour are affected by:

The frequency of interaction: the greater the frequency, the greater the possibility of both sides learning to correctly interpret the attitudes of the other. 
The multiplicity of interaction: the greater the variety of (positive) actions that link the two actors, the more broadly they will coincide in the dyad.

The strength of interaction: stronger links in positive relationships lead to stronger agreement between members of the dyad.

The asymmetry of interaction: in relationships based on authority, asymmetry can prevent comparison or provoke disagreement, while in relationships built on esteem, subordinates can use their superiors as role models (Erickson 1988).

\section{The triadic level}

The concepts of structural balance and transitivity (Wasserman and Faust 1994) have been used to predict similarity between actors, based on the mere stability of the structure. Stability implies that, in a triadic structure, a non-adopter linked to two others that have already adopted will end up adopting as well. Krackhardt (1998, 1999) and Krackhardt and Kilduff (2002) point out that dyads joined by Simmelian ties (i.e. dyads enclosed in a clique of three people) eventually reach a stronger consensus than members of other dyads. Extending these arguments, one might think that one agent linked to another two that adopt an innovation more intensely; and that someone more strongly linked to agents that have adopted more intensely; eight or that promote the innovation, and at the same time are strongly linked to each other, will end up adopting even more way than Could be predicted in a merely diadic analysis.

\section{Network level}

By comparing centralized networks with more diffuse structures, such as those that have a centre-periphery design, paves the way for diffusion once the element being diffused reaches the nucleus of leaders of opinion or other agents with a high level of influence (Rogers 2003).

\section{Objectives and justification}

This research was carried out on the basis of certain premises:

1. The adoption and use of technologies does not solely depend on their attractiveness and potential but also on contextual factors (Sieber and Valor 2005)

2. The use of participative social technologies is becoming widespread and particularly amongst younger generations due to the fact that new internet applications imitate the way in which people interact and collaborate in an increasingly perfect fashion (Gamero 2007).

3. Technologies have an impact on young people by modifying their life styles, especially through mobile technology, to generate new ways of expressing themselves, new ways of relating to others, new forms of learning, new languages for communication, the development of new values, and behavioural skills and competences (Tapscott 1998; Chu 1997). 
We selected the mobile phone for our study as it is one of the most recent technological advances that has meant a substantial improvement not only in the area of telecommunications, but in countless other social or economic activities. In just a few years, it has gone from being a merely residual tool to outgrowing the number of landline telephones. The development of information and electronic technology has meant that the use of the mobile phone is not restricted to traditional calls, the functions of which were limited to verbal communication. Instead, its current applications (and immediate possibilities) are incomparably greater. The mobile phone is used as a means of communication between two people or between groups, it serves as an immediate access point to information, the sending and reception of messages, as well as a connection to the internet. It has photography and digital video applications and a variety of other applications based on what would have been unimaginable technology just a few years back.

The attractiveness of this equipment, the innumerable possibilities it holds for communication, technology and leisure, as well as its accessibility, have meant that the current population that use it is not only greater in number but also of a lower average age, as the type of applications it offers is particularly attractive to young people and teenagers. More sophisticated tools are continually being devised with greater possibilities, applications and accessibility, both with regard to the cost of the equipment and in terms of the phone line itself that supports the communication. All these factors combined go to explain why it is the younger generation and teenagers who are making the most of these advances and why they have become the targets for marketing strategies.

Despite the unquestionable advantages and opportunities it provides (and perhaps in part due to this fact), one of the main problems implicit in this technology (and perhaps the most important) is that of abusive use or even dependence upon an instrument that, in principle, has undeniable advantages compared to previous much more primitive devices. Dependence on the mobile phone represents one of the most characteristic forms of what is currently called technological addictions, referring to a type of behavioural addiction, in which the processes of dependence and abuse are not toxic substances, but rather behavioural activities.

In the presentation of this study, we refer only to the analysis of technology associated with mobile phones although the line of research has been broadened to include other types of technology such as microinformation platforms.

In terms of technology, since their commercial launch in the 1980s up to the present day, there have been three generations of mobile phones which have brought improvements in the area of telecommunications, the internet and also in the multifunctionality of this tool, which has morphed from simply being a portable phone to becoming a more technologically advanced consumer tool which has incorporated the most novel elements of electronic engineering. All of this has not only favoured its spectacular implantation in the market but also modified both the form of communication and attitudes towards the mobile phone itself. It has meant a revolution in the area of interpersonal relations and leisure activities, particularly in the younger generation and teenagers who are currently 
the sector which makes the most use of the technological development in these tools and are the main acquirers of new market advances, which makes them the favourite target for merchandising techniques by the main telephone operators and mobile phone manufacturers.

According to the report by the Telecommunications Observatory and Information Society at the time of the empirical study (April-June 2007), the mobile phone accounted for $43.2 \%$ of the total cost of services that used new technologies in the home (ICT) (landline telephones, mobile phones, internet, digital or cable TV) with a total of $€ 5,108$ million spent during that year.

In terms of the number of phones, mobiles now exceed the number of landline phones in the home (85.7\% of homes possess a mobile phone compared to $82.7 \%$ with a landline). However, if we focus on penetration with regard to the population, in other words, on the number of lines according to the total number of inhabitants, the results are even more spectacular with the penetration rate already standing at $110.5 \%$ in October 2007, i.e. exceeding the number of inhabitants by over $10 \%$. These figures are even more significant if we bear in mind that there are sectors of the population (young children and the very old) that do not normally use mobile phones.

Currently in Spain, $74 \%$ of mobile phone use is for personal reasons and the majority $(66 \%)$ work on a contract system, as opposed to just over $30 \%$ who use the prepaid card system, the proportion of which is dropping because company marketing campaigns encourage contracts.

It is quite likely that the mobile phone will even outstrip the personal computer. This is contributed to by the fact that the phones that appear on the market possess new, technologically more advanced resources which go on to become 'necessary' for the actual use of the phone, in addition to the old economic adage of 'supply creates demand' through which what are currently considered to be possibilities become necessities shortly afterwards. To this we must add the fact that, amongst teenagers (the age group that contributes the largest percentage of sales) it is a tool that brings identity, is subject to fashions and is an object of desire. The market is extraordinarily dynamic and at present, a third of all users have a mobile phone that is less than a year old.

For this reason, mobile phone sales are expected to continue to rise. It is in fact a very active market in which new functionalities are brought out (particularly related to the internet) and added to those that already exist in communication reproduction and recording of music, photography and video. Currently, important internet firms such as Microsoft, Yahoo, MySpace, Google, Meetic, and eBay have been dedicating resources and investments to include their products in mobile phones. In the case of Microsoft, its Windows Mobile system has already been preinstalled in 70 models from 15 different manufacturers and in Japan, a society that can be used as a reference for predicting the evolution of technology, Mobagay Town (which is the fastest growing social network) only functions with mobile phones that connect to the internet. In fact, half of all mail currently sent in Japan is done so by mobile phone. 


\section{Research procedure}

The total sample was made up of 1,556 teenagers of between 11 and 18 years of age. The average age as well as the median was 15 years old, while the most frequent age was 13 . The dispersion of these values was 1 year and 10 months, and asymmetry was practically negligible $(\mathrm{As}=0.04)$. However, the distribution strayed from standard distribution because, in line with the terminology proposed by Pearson (1906), it followed a Platykurtic distribution $(\mathrm{Cu}=-1.8)$.

Figure 1 shows the proportion of teenagers by age range. As shown, the proportion of participants by age is very similar, with the exception of nine students ( $0.6 \%$ of the sample) from the first year of Spanish secondary school, who were 11 years old at the time they were asked to do the survey, but who were about to be 12. $18 \%$ of the participants were 13 years old, followed by $16.6 \%$ who were 14 years old, $16.5 \%$ were $17,16.1 \%$ were $15,15.2 \%$ were 16 and finally, the lower proportions included $9.2 \%$ who were 12 and $7.2 \%$ who were 18 years old.

In terms of gender, the proportion of male and female respondents in the sample was almost identical. The sample was made up of 769 men $(50.1 \%)$ and of 766 women $(49.9 \%)$. A total of 21 people did not answer the question relating to gender.

Sample characteristics were also analysed with regard to level of studies. All participants were at school in different Spanish cities. The sample was also analysed with respect to the amount of money the teenagers had available to them each week for their own general expenses. The teenage respondents had an average of $€ 16$ for general costs, while the median and mode were $€ 10$ per week. More specifically, and according to age, teenagers between 12 and 14 had an average of $€ 10.29$ per week for general expenses, those between 15 and 16 years of age had an average of $€ 17.48$ and those between 17 and 18 had an average of $€ 24.47$.

The differences between each of the available money for general expense averages according to age were statistically significant $(F=66.99 ; P<0.001)$.

Fig. 1 Proportion of teenagers by age

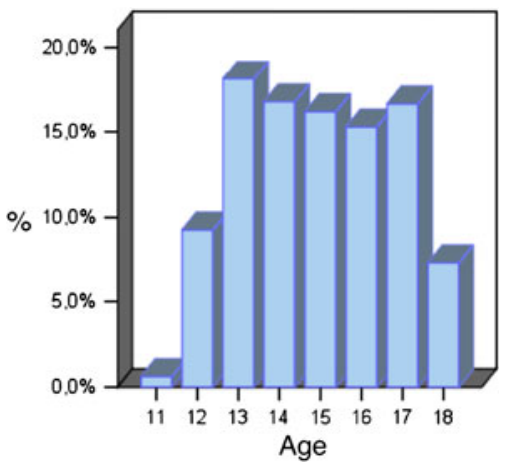




\section{Study results}

Number of mobile phones

At a descriptive level, $94.9 \%$ of the surveyed teenagers owned a mobile phone, while only $5.1 \%$ did not. Out of the participants who had a mobile phone, each of them had had an average of four mobile phones each. To be precise, $66.2 \%$ of respondents had four mobile phones or less and of the rest, $33.8 \%$ had more than four. In terms of age, teenagers from 12- to 14-years old had an average of three mobiles, 15-16-year olds had an average of four and 17-18-year olds had an average of five mobiles.

Period of time during which they had owned a mobile phone

The average length of time survey respondents had owned a mobile phone was 3 years and 9 months with a dispersion of 1 year and 11 months. In terms of age, younger respondents had not only had fewer mobiles up to that time but also, as was to be expected, they had owned a mobile for a shorter period of time. Teenagers between 12 and 14 had a mobile for an average of 2 years and 9 months, those between 15 and 16 had them for 3 years and 11 months and the 17-18 year-olds for an average of 5 years and 1 month.

\section{Form of acquisition}

With regard to the form of acquisition of the first mobile phone, $54.4 \%$ of the surveyed teenagers were given the phone by their parents, family members or friends because they had insisted they wanted one, $28.9 \%$ of participants were given the phone by their parents, family members or friends even though they had not asked for one, $5.9 \%$ bought it themselves, $0.9 \%$ found it, $0.1 \%$ were given a phone at work, $1.3 \%$ were given it by the telephone company and, finally, $8.5 \%$ obtained it via other non-specified means. $1.5 \%$ of respondents did not answer this question.

Table 1 Daily time spent on mobile phones in minutes

\begin{tabular}{lcc}
\hline Minutes & Weekday $(\%)$ & Weekend $(\%)$ \\
\hline $\bar{X}$ Daily & 26.06 & 36.25 \\
$0-10$ & 35.1 & 27.5 \\
$10-20$ & 7.6 & 10.3 \\
$20-30$ & 7.2 & 7.4 \\
$30-60$ & 7.5 & 7.1 \\
$\geq 60$ & 0.2 & 3.31 \\
Void & 42.5 & 48.4 \\
\hline
\end{tabular}


Table 2 Daily time spent on mobile phones in minutes according to gender

\begin{tabular}{llllll}
\hline \multirow{2}{*}{ Minutes } & Weekday & & & \multicolumn{2}{l}{ Weekend } \\
\cline { 2 - 3 } \cline { 5 - 6 } & Male (\%) & Female (\%) & & Male (\%) & Female (\%) \\
\hline $\bar{X}$ Daily & 19.22 & 33.18 & 26.28 & 35.46 \\
$0-10$ & 64.3 & 55.4 & & 42.2 & 34.6 \\
$10-20$ & 12.6 & 15.5 & 16.9 & 18.7 \\
$20-30$ & 8.9 & 8.9 & 13.7 & 15 \\
$30-60$ & 8.9 & 11.6 & 15.3 & 13 \\
$\geq 60$ & 5.3 & 9.6 & 11.9 & 18.7 \\
\hline
\end{tabular}

Table 3 Daily time spent in minutes on mobile phone according to age

\begin{tabular}{lccccccc}
\hline & \multicolumn{2}{l}{ Weekday $(\%)$} & & \multicolumn{3}{l}{ Weekend $(\%)$} \\
\cline { 7 - 8 } Age & $12-14$ & $15-16$ & $17-18$ & & $12-14$ & $15-16$ & $17-18$ \\
\hline $\bar{X}$ Daily & 18.97 & 29.45 & 26.16 & & 28.79 & 37.23 & 45 \\
$0-10$ & 37.9 & 31.3 & 27.4 & & 31.1 & 24.9 & 19 \\
$10-20$ & 6.2 & 7.6 & 8.7 & 9 & 9.1 & 12.5 \\
$20-30$ & 7.6 & 6 & 6.8 & & 7.5 & 6 & 7.3 \\
$30-60$ & 5.8 & 7.6 & 9.2 & & 5.8 & 6 & 9.8 \\
$\geq 60$ & 2.9 & 5.8 & 8.4 & & 6.1 & 8.4 & 11.7 \\
\hline
\end{tabular}

Time spent on the phone

During the week, the surveyed teenagers spent an average of 26 min per day on the phone between calls and messages and an average of $35 \mathrm{~min}$ at the weekend. During the week, $35.1 \%$ of the teenagers used their phone for $10 \mathrm{~min}$ or less, $7.6 \%$ from 10 to $20 \mathrm{~min}, 7.2 \%$ from 20 to $30 \mathrm{~min}, 7.5 \%$ from $30 \mathrm{~min}$ to an hour and $0.2 \%$ from one to $6 \mathrm{~h}$ which was the maximum registered time. $42.5 \%$ did not respond to this question. On the other hand, at the weekend, $27.5 \%$ of teenagers spent $10 \mathrm{~min}$ or less per day on the phone, $10.3 \%$ between 10 and $20 \mathrm{~min}, 7.4 \%$ between 20 and $30 \mathrm{~min}, 7.1 \%$ from $30 \mathrm{~min}$ to an hour and $3.31 \%$ between 1 and $6.5 \mathrm{~h}$ which was the maximum registered time. $44.4 \%$ did not respond to this question (Table 1).

Statistically significant differences were also found between male and female respondents in the average time spent between messages and calls per week $(F=27.39 ; P<0.05)$ and at the weekend $(F=28.07 ; P<0.05)$. As can be seen in Table 2, women spend more time per day on messages and calls, both during the week and at weekends.

In addition, statistically significant differences were also found in the time spent per day on calls and messages both during the week $(F=13.55 ; P<0.001)$ and at weekends $(F=7.25 ; P<0.001)$. However, the a posteriori HDS de Tukey test revealed that there were no statistically significant differences between all the time 
Table 4 Frequency of daily use of the mobile phone

\begin{tabular}{|c|c|c|c|c|c|c|}
\hline & \multicolumn{2}{|l|}{ Calls } & \multicolumn{2}{|l|}{ Messages } & \multicolumn{2}{|c|}{ Missed calls } \\
\hline & $\begin{array}{l}\text { Weekday } \\
(\%)\end{array}$ & $\begin{array}{l}\text { Weekend } \\
(\%)\end{array}$ & $\begin{array}{l}\text { Weekday } \\
(\%)\end{array}$ & $\begin{array}{l}\text { Weekend } \\
(\%)\end{array}$ & $\begin{array}{l}\text { Weekday } \\
(\%)\end{array}$ & $\begin{array}{l}\text { Weekend } \\
(\%)\end{array}$ \\
\hline $\bar{X}$ Daily & 2.91 & 3.98 & 3.87 & 4.52 & 9.19 & 10.41 \\
\hline $0-3$ & 53 & 40.2 & 49.7 & 41.7 & 25 & 21.9 \\
\hline $3-6$ & 14.5 & 22.3 & 13 & 18.3 & 10.9 & 12 \\
\hline $6-9$ & 3.3 & 7 & 4.1 & 5.3 & 4.8 & 4.6 \\
\hline $9-12$ & 2.2 & 3.7 & 4.3 & 4.8 & 9.1 & 7.1 \\
\hline $12-15$ & 1.2 & 1.7 & 1.6 & 2.4 & 3.3 & 4.5 \\
\hline$\geq 12$ & 0.8 & 1.1 & 2.9 & 3 & 12.2 & 14.5 \\
\hline Void & 25.1 & 24 & 24.4 & 24.4 & 34.6 & 35.3 \\
\hline
\end{tabular}

Table 5 Most frequent use of the mobile phone by time of day

\begin{tabular}{lr}
\hline Time of the day & $\%$ \\
\hline In the morning & 0.8 \\
At lunchtime & 1.3 \\
In the afternoon & 19.5 \\
At night & 6.2 \\
At any time & 27.5 \\
At lunchtime and in the afternoon & 5.9 \\
In the afternoon and at night & 28.3 \\
At lunchtime, in the afternoon and at night & 4.2 \\
Other responses & 6.3 \\
Void & 1.4 \\
\hline
\end{tabular}

averages spent per day on mobile phones across all the age ranges, both during the week and at the weekend. Precisely, there were statistically significant differences between the time averages spent by all the age ranges except for the average for the 15-16 and the 17-18 age groups (Table 3).

Frequency of use

With regard to the frequency of use of the mobile phone, Table 4 first shows the average daily calls, messages and 'missed calls' sometimes called 'dodges' either during the week or at the weekend. According to the results, the average number of missed calls or dodges is greater than the number of messages and those messages are, in turn, greater than the number of calls and in all cases, numbers increase at the weekend as compared to expenses during the week. Second, the proportion of teenagers according to daily use on mobile phones is shown. It should be highlighted that the great majority of these teenagers use the phone three or four times a day for such purposes, be they calls, messages or 'missed calls'. Statistically significant differences between male and female respondents were found with 
Table 6 Proportion of teenagers by place with the most frequent use of mobile phones

\begin{tabular}{lr}
\hline Places of common use & $\%$ \\
\hline At home & 5.9 \\
In the street or park & 7.7 \\
In my bedroom & 5 \\
At school & 0.3 \\
In the pub, bar or disco & 0.4 \\
Anywhere & 40.9 \\
At home in the street or in the park & 7.4 \\
At home and in my room & 5.5 \\
In the street and in my room & 6.4 \\
At home, in the street or on the park and in my room & 8.7 \\
Other responses & 11.8 \\
Void & 1.1 \\
\hline
\end{tabular}

Places of most frequent use as a $\%$

regard to average consumption of mobile phones $(F=9.022 ; P<0.001)$, females made a greater number of calls, messages and missed calls or dodges per day than males.

Times of the day phones are most used: in relation to the time of the day in which the mobile phone is most used, Table 5 shows that $28.3 \%$ of the surveyed teenagers stated that they used their mobile more in the afternoon and at night, $27.5 \%$ state that they used their mobile at any time of day, $19.5 \%$ in the afternoon, $6.2 \%$ at night, $5.9 \%$ around lunchtime and in the afternoon and $4.2 \%$ around lunchtime, in the afternoon and at night. $1.4 \%$ of participants did not reply to this question.

Frequency of place

In terms of the place where the mobile phone is most commonly used, Table 6 shows that $40.9 \%$ of the surveyed teenagers stated they used their mobile phone regardless of place, $8.7 \%$ at home, in the street, in the park or in their bedroom, $7.7 \%$ in the street or the park, $7.4 \%$ at home, in the street or in the park, $6.4 \%$ in the street or the park or in their bedroom, $5.9 \%$ at home, $5.5 \%$ at home and in their bedroom and $5 \%$ in their bedroom. $1.1 \%$ of participants did not respond to this question.

\section{Availability}

From the point of view of availability, $51.3 \%$ of the surveyed teenagers stated that they always had their mobile phones connected although sometimes on silence or vibration mode. A much smaller proportion of teenagers stated that they always had their mobiles connected, but always switched them off in places where their use was forbidden, $6.5 \%$ always had them connected, $6.3 \%$ always had them connected, but sometimes in silence or vibration mode in places where their use was forbidden 
Table 7 Proportion of teenagers according to what they use their mobile phones for monthly expenditure

\begin{tabular}{lrrrrr}
\hline Mobile phone functions & Never & Seldom & Sometimes & $\begin{array}{r}\text { Quite } \\
\text { often }\end{array}$ & $\begin{array}{c}\text { Many } \\
\text { times }\end{array}$ \\
\hline To maintain contact with my friends/loved ones & 2.2 & 4.2 & 12.1 & 27.3 & 54.2 \\
Because I feel lonely & 63.3 & 24.7 & 8.8 & 1.6 & 1.5 \\
Because sometimes I cannot use the landline phone & 32.8 & 20.3 & 27.7 & 10.5 & 8.7 \\
In cases of emergency & 9.7 & 25.2 & 26.6 & 14.8 & 23.8 \\
To be located at all times & 4.1 & 7.3 & 15.4 & 26.6 & 46.6 \\
Because I like to explore the technical characteristics & 35.2 & 27.5 & 21.1 & 9.1 & 7.1 \\
To give or obtain information & 30.3 & 27.6 & 24.4 & 10.4 & 7.4 \\
To send or receive fun messages & 23.9 & 23.4 & 22.7 & 13.2 & 16.8 \\
To occupy my time when I feel bored & 22.4 & 26.7 & 24.2 & 12.9 & 13.7 \\
To play & 26.4 & 34.6 & 22.6 & 8.8 & 7.6 \\
To see the time or date or as an alarm or electronic diary & 6.3 & 11.6 & 19.8 & 26.1 & 36.1 \\
\hline
\end{tabular}

and $5.8 \%$ always had them connected and sometimes in silence or vibration and turned off at night so that they were not disturbed while sleeping. $1 \%$ of respondents did not answer this question.

Mobile phone functions

Table 7 shows the proportion of teenagers according to the use they make of their telephones. In other words, when they use the mobile, $81.6 \%$ stated that very frequently, it was to stay in touch with friends or loved ones, $73.3 \%$ stated that very frequently, or on many occasions, it was to be located at all times and $62.2 \%$ claimed that very frequently it was to consult the time or date or to use it as an alarm or electronic diary. Conversely, $88 \%$ of respondents stated they never or rarely used their mobile phone because they felt lonely, $62.7 \%$ stated that they never or rarely used it because they liked to explore the technical characteristics of the phone and finally, $61 \%$ of the surveyed students stated that they never or rarely used it for playing.

\section{Monthly expenditure}

Average monthly spending on mobile phones was $€ 17.71$ although the most frequent amount was $€ 10.15 .2 \%$ of the respondents spent $€ 5$ or less, $27.6 \%$ spent between $€ 5$ and 10 a month, $14.9 \%$ spent between $€ 10$ and 15 a month, $18.8 \%$ spent between $€ 15$ and $20,6.6 \%$ between $€ 20$ and $25,7.3 \%$ spent between $€ 25$ and 30, $4.3 \%$ spent between $€ 30$ and 40 and $5.3 \%$ spent from $€ 40$ and 150 a month which was the highest recorded amount. As can be observed in Fig. 14, teenagers 
that had a contract spent more on mobile phones with an average expenditure of $€ 22.23$ per month, than teenagers that used a prepaid system, with an average monthly spending of $€ 13.96$. These differences were statistically significant $(F=107.73 ; P<0.001)$. Moreover, a direct and positive relationship was also found between weekly available money and monthly economic expenditure on mobile phones; in other words, the greater the available budget, the greater the monthly expenditure on mobile phones $(r=0.28 ; P<0.01)$.

\section{Forms of financing}

$69.99 \%$ of the respondents' mobile phone bills were paid by their parents or family, $18.90 \%$ of participants paid for it themselves with pocket money from parents or family, $5.9 \%$ paid for it themselves with money from working, $1.5 \%$ stated that they sometimes paid for it themselves and sometimes it was their parents who paid, $3.6 \%$ paid half with their parents/family, $0.75 \%$ had it paid by parents or family though if they went over a certain amount they had to pay for it themselves, $0.62 \%$ paid for it with their own savings and the remaining $0.89 \%$ of surveyed teenagers had other means of non-specified financing.

\section{Research conclusions}

Despite its recent appearance, the mobile phone is an instrument that already forms part of our culture and especially that of teenagers, as they practically all have one. To be precise, $95 \%$ of teenagers between 12 and 18 years of age have a mobile phone and the proportion goes up to over $99 \%$ for the 17-18-year-old age group. Since the prices of these devices have gone down considerably in recent years, in the majority of cases, they are given as gifts by parents or family members after the teenagers insist they need or want one although a high proportion of these youngsters (nearly $30 \%$ ) were given a mobile as a present although they had not asked for one. In this case, it is normally provided as a control or safety measure by the parents, although for teenagers, the mobile represents a tool that ironically enough offers independence.

The majority of teenagers have had several phones (around four mobiles on average) with obvious differences according to age. In addition, the mobile phone is an instrument with a short life span due to the continuous technological innovations that these instruments incorporate which users then demand as essential. In fact, the mobile is the home technology that has increased the most, both in number of devices and in cost. It can be underlined that the mobile phone is a tool for daily use and an object of desire for adolescents.

However, the mobile is not a telephone alone. It has numerous other functions as well as being a communication tool. They are much more versatile than landline telephones, especially since the incorporation of digital technology. In addition to being used to make traditional calls, mobiles can also be used for sending messages, multimedia, etc. In terms of communication functions, teenagers send more messages than calls and more 'missed calls' than SMS. This has led to a 
modification in the patterns of social relationships, dates, forms of interpersonal communication, etc.

One of the main advantages of the mobile is that it can be used (and indeed it is) almost anywhere, even in places where its use is not recommended or appropriate. It is not, though, merely a matter of mobility, as the majority of teenagers always have their mobile connected, which also means continuous availability. In addition, the fact that the calls are registered, even when the phone is not answered 'obliges' the person who has received the call to return it, and thus communication patterns are established which, at the very least, are different from landline phone patterns.

Another significant difference between mobile and landline phones is that, while the latter is associated with an address (family, professional, etc.), mobiles are associated with a particular person. If we bear in mind that mobiles are used anywhere and everywhere and for all types of occasions, that they are always available and that they are associated with a person, we are talking about something more than mobility. More than a mobile, it would be better to call it a 'personal telephone'. And, taking into account the countless functions of this instrument, even the noun 'telephone' should be substituted for something more in line with its multifunctionality.

Therefore, apart from voice calls, missed calls and messages, teenagers use mobiles to listen to MP3 music, listen to the radio, watch videos, take photos, record or capture videos (or audio), play with games on the mobile or with others online, use the internet (email, messenger, visit web sites, blogs...), etc.

However, the functions of mobile phones are not only communication, technologies and leisure but also they serve as a tool for establishing personal relationships. People use them when they are alone or bored and when they show symptoms of anxiety or dysphasia. If we bear in mind that adolescence is characterized precisely by the frequency of emotional, transitory imbalances and the use and abuse of the mobile phone in teenagers in Spain, it can be assumed that the mobile will become a frequent and necessary tool.

\section{Expenditure and consumption}

Considerable differences can be observed in monthly expenditure for mobile phones, especially in terms of age and gender, as we will go on to see. Regardless of this, one of the most relevant conclusions is that expenditure will always be greater in the contractual mode ( $€ 22.23$ on average) than in prepaid solutions (€13.96). In addition, spending is always greater regardless of other variables (like budget for expenses). The fact that teenagers spend less in prepaid mode can be explained due to what is termed in learning psychology as 'stimulus control', in other words, control of the antecedents that influence behaviour. In addition, the prepaid mode also favours the user's awareness of what they are spending their money on, something that is often more easily hidden in contracts. In fact, one of the problems that has come to light in this study is that teenagers are not normally aware of spending, even when this becomes excessive. Only $7 \%$ of teenagers think that they spend more than other boys or girls of their age. 
As a conclusion to this point, despite the fact that telephone operating companies offer contract conditions that make tariffs cheaper per call than using prepaid cards, consumption increases in the end and spending is much greater than that incurred under a prepaid system.

Another of the results to be underlined in this study is the fact that it is the parents who normally pay their children's telephone bill. $70 \%$ of teenagers indicate that their parents pay for the cost of their telephones. Obviously, this makes it difficult for teenagers to learn to control consumption, as well as becoming a source of family problems, as we have been able to verify from the questionnaire on problems derived from the use of the mobile phone. Therefore, one of the recommendations for avoiding parent-child conflict arising from abusive use of mobile phones is for teenagers to have an amount of money which they have to administer themselves to cover the cost of their mobile, and that mobile should be contracted using the prepaid system.

Differences of gender with regard to mobile phones

Some of the more relevant results of this study clearly show that there are notable differences in the use of mobile phones between girls and boys. These can be summarised in several sections:

Patterns of mobile phone use

Despite the fact that we did not find differences in the number of calls sent or received, girls used the mobile phone more than boys, both in terms of the number of messages and in the number of missed calls and the time spent on using the mobile phone both during the week and at weekends. Thus, we can state that the mobile phone is an instrument that is part of daily life and which is more important for girls than boys. Moreover, girls dedicate more time and more economic resources to mobiles. This fact should be highlighted because teenage girls normally have less cash available than boys in their weekly budget. Therefore, despite having less money available per week (girls have $€ 14.75$ as opposed to boys who have $€ 17.23$ ), girls spend more on mobile use (€19.60 a month) than boys (who spend $€ 15.50$ a month).

In short, teenagers dedicate more and more time and ever increasing amounts of economic resources to mobile phones. This expenditure is another indirect measure of how important mobile phones are for them.

Attitudes towards mobile phones

Attitudes tend to be in accord to real behaviour, as a means of avoiding conflicts between what is thought and what is done. Moreover, any preventive programme should also attend to this type of cognitive variable if any rational use is to be given to mobile phones. In any case, it is necessary to justify the need to establish such preventive measures. 
In this sense, girls do not only use the mobile more than boys but also have more positive attitudes towards it. They consider to a larger extent than boys that 'the mobile phone increases the possibility of being in touch with people', that 'having a mobile today is essential' or that 'having a mobile phone is as important as having clothes to wear or eating', while boys think more often than girls that (although there are no significant differences) The mobile phone is a useless expense' or that 'using the mobile phone is an inconvenience to others when used in public places'.

\section{Problems associated with expenses from mobile phones}

One of the main complaints from parents about the use of mobile phones is the excessive cost that their sons and daughters incur in. As mentioned above, girls have fewer economic resources, but spend more than boys on their mobile phones, which thus entails a bigger economic sacrifice for them. However, there are problems derived from mobile phone spending both in cases where teenagers pay their own bills and in cases where costs are paid by the parents. In any case, for girls, this means that problems stemming from excess mobile phone use are greater than for boys, regardless of who pays the bill or buys the card. Girls scored higher (they had more problems) than boys in 11 out of 12 items that made up the scale of economic problems caused by mobile costs.

\section{Mobile phone functions}

One of the most relevant results of this research, which is much broader than what is detailed here, is the analysis of the different functions for which the mobile is used. As we have indicated, the mobile is not only a telephone but also is actually a multifunctional instrument at the service of communication, leisure, information and even personal growth and social adaptation. The numerous differences found between boys and guys in terms of the mobile functions they each use can therefore be explained.

As a general rule, girls use the mobile more as a tool for interpersonal communication, as well as a psychological tool that can be used to dispel unpleasant states of mind. They use it more often than boys to overcome boredom, manage anxiety or in moments where they are alone or feeling down. They also feel more affected than boys when they do not receive messages or calls from others. Some of the most significant replies in the case of girls were that they used the mobile for 'staying in contact with my friends and loved ones', 'because I feel lonely', 'to send or receive fun messages' or 'to pass the time when I am bored'. Boys, however, use the technological functions and applications more than girls, such as games, downloads from the internet, use of electronic devices, etc. The only tool used more by girls is the camera, but this might be in line with the results obtained because, although it is a technological instrument, it is at the service of interpersonal relations, while others such as games are individual. Some of the more significant responses in the case of boys were that they used it because 'I like to explore the technical characteristics of the device', 'to play', 'to use the internet' (email, 
Messenger, visit web pages, blogs...)', 'download games, music, tones, files, etc.' or 'play with the games I have on the mobile'.

These results are particularly significant in the area of dependencies. Any addictive behaviour begins through the pleasure or desire it provokes, in other words, to obtain the desired results, which in the case of the mobile phone means to favour communication, maintain interpersonal relations, increase availability, use highly attractive technologies, etc. However, what is particularly relevant and unique about addictions is that processes of dependence finally appear, and the aforementioned objectives can only be achieved through addictive behaviour (use of the mobile) and if we take things a step further, being deprived of the mobile provokes high levels of unease that are only alleviated by consuming once more (in this case using the mobile).

Therefore, the functions girls use on their mobile and especially the fact that they use it as a psychological tool (to establish and maintain interpersonal relationships, and for overcoming affective states such as boredom or dysphoria) should be borne in mind to prevent future dependencies, as all addictions are characterised by the fact that addictive behaviour is used to overcome unpleasant personal situations.

\section{Mobile and age}

Despite the fact that adolescence is a relatively short period, it is not at all homogenous. The first stages, closer to childhood or puberty, and the final ones, related to the transition to adulthood should be differentiated. We, therefore, divided the sample into three groups that we considered to be more psychologically significant (12-14; 15-16 and 17-18). Similarly, to the case of gender, we analysed the different uses of the mobile phone, the problems associated with it, as well as the functions for which it is used, which in this case, were according to age. We observed that there was a progressive increase in the main parameters of use (time spent using the mobile, numbers of calls and messages sent, etc.) the older the group. The mobile is part of teenagers' lives and functions are progressively added as they get older. However, despite the fact that there was an increase in spending, economic resources also increased, meaning that the percentage of spending that went on mobile phones was reduced when comparing older groups against younger groups.

Another difference observed was the progressive adoption of the contract system. Thus, although at an early age the prepaid card system is the most common, as age increases, this is replaced by the contract system, up to the point where in the 17-18 age group contracts exceed the number of prepaid cards. The differences appear between the first two groups. Although the prepaid mode is used for in the younger age groups, this is soon replaced (around age 15) by the contract mode. This is especially significant because the type of contract influences expenditure.

Normally, teenagers in the 15-16 age group have a more positive image of mobile phones and a less negative view than the 17-18 group. This coincides with typical adolescent behaviour, while older teenagers may have a more balanced view of the instrument. This result suggests that it is necessary to analyse the changes 
which occur in the use of mobiles over time through the development of a longitudinal perspective and methodology.

With regard to the problems associated with mobile expenses, we find differences in terms of whether bills are paid by the teenagers themselves or by their parents. In the latter case, problems increase as spending rises; relational problems appear with parents and warnings are given from around the age of 15. These differences are not observed when the teenagers pay their own bills. As costs also increase with the change from a prepaid card to a contract, there are clearly two recommendations to be made to avoid problems associated with an excessive increase in mobile spending. One is to maintain the prepaid card mode. The other is to ensure that it is the teenagers themselves who have to fund their own expenses. This is obviously not as easy as the solution prescribed by mobile phone companies but on an educational scale it appears to be the best option.

\section{References}

Becker, M. H. (1970). Sociometric location and innovativeness: Reformulation and extension of the diffusion Model. American Sociological Review, 35(2), 267-282.

Borgatti, S. P. (2005). Centrality and network flow. Social Networks, 27, 55-71.

Burt, R. S. (1978). Cohesion versus structural equivalence as a basis for network subgroups. Sociological Methods \& Research, 7, 189-212.

Burt, R. S. (1987). Social contagion and innovation: Cohesion versus structural equivalence. American Journal of Sociology, 92, 1287-1335.

Burt, R. S. (1992). Structural holes: The social structure of competition. Cambridge: Harvard University Press.

Burt, R. S. (2005). Brokerage and closure: An introduction to social capital. Oxford: Oxford University Press.

Chu, J. (1997). Navigating the media environment: How youth claim a place through zines. Social Justice, 24(3), 71-85.

Dagenne, A., \& Forsé, M. (1999). Introducing social networks. London: Sage Publications.

Dinar, A., Karagiannis, G., \& Tzouvelekas, V. (2007). Evaluating the impact of agricultural extension on farms' performance in Crete: A nonneutral stochastic frontier approach. Agricultural Economics, $36,135-146$.

Erickson, B. H. (1988). The relational basis of attitudes. In B. Wellman \& S. D. Berkowitz (Eds.), Social structures: A network approach. New York: Cambridge University Press.

Feder, G., \& Savastano, S. (2006). The role of opinion leaders in the diffusion of new knowledge: The case of integrated pest management. World Development, 34(7), 1287-1300.

Friedkin, N. E. (1984). Structural cohesion and equivalence explanations of social homogeneity. Sociological Methods and Research, 12, 234-261.

Friedkin, N. E. (1999). Social influence networks and opinion change. Advances in Group Processes, 16, $1-29$.

Friedkin, N. E., \& Johnssen, E. C. (1997). Social positions in influence networks. Social Networks, 19, 209-222.

Gamero, R. (2007). Servicios basados en redes sociales, la web 2.0. In Investigación y marketing, Vol. 97, pp. 16-20.

Granovetter, M. (1973). The strength of weak ties. American Journal of Sociology, 78, 1360-1380.

Granovetter, M. (1982). The strength of weak ties: A network theory revisited. In P. V. Marsden \& N. Lin (Eds.), Social structure and network analysis. Newbury Park, CA: Sage.

Hansen, M. T. (1999). The search-transfer problem: The role of weak ties in sharing knowledge across organization subunits. Administrative Science Quarterly, 44, 82-111. 
Krackhard, D. (1998). Simmelian ties: Super strong and sticky. In R. Kramer \& M. Neale (Eds.), Power and influence in organizations. Thousand Oaks: California.

Krackhardt, D. (1999). The ties that torture: Simmelian tie analysis in organizations. Research in the Sociology of Organizations, 16, 183-210.

Krackhardt, D., \& Kilduff, M. (2002). Structure, culture and Simmelian ties in entrepreneurial firms. Social Networks, 24, 279-290.

Levin, D. Z., \& Cross, R. (2004). The strength of weak ties you can trust: The mediating role of trust in effective knowledge transfer. Management Science, 50, 1477-1490.

Liu, W. T., \& Duff, R. W. (1972). The strength in weak ties. The Public Opinion Quarterly, 36, 361-366.

Marsden, P. V. \& Friedkin, N. E. (1994). Network studies of social influence. In: Wasserman, S. \& Galaskiewicz, J. (Eds.), Advances in social network analysis: Research in the social and behavioural sciences. London: Sage.

McPherson, M., Smith-Lovin, L., \& Cook, J. M. (2001). Birds of a father: Homophily network. Annual of Sociology, 27, 415-444.

Michaelson, A., \& Contractor, N. S. (1992). Structural position and perceived similarity. Social Psychology Quarterly, 55(3), 300-310.

Mizruchi, M. S. (1993). Cohesion, equivalence and similarity of behaviour: A theoretical and empirical assessment. Social Networks, 15, 275-307.

Monge, P. R. \& Contractor, N. S. (2003). Theories of communication networks. New York: Oxford University Press.

Nyblom, J., Borgatti, S., Roslakka, J., \& Salo, M. A. (2003). Statistical analysis of network data: An application to diffusion of innovation. Social Networks, 25, 175-195.

Obstfeld, D. (2005). Social networks, the Tertius Iungens orientation, and involvement in innovation. Administrative Science Quarterly, 50, 100-130.

Reagans, R., \& McEvily, B. (2003). Network structure and knowledge transfer: The effects of cohesion and range. Administrative Science Quarterly, 48, 240-267.

Rogers, E. M. (2003). Diffusion of innovations (5th ed.). New York: Free Press.

Sieber, S., \& Valor, J. (2005). Criterios de adopción de las tecnologías de información y comunicación, e-Business Center Pricewaterhouse Coopers \& IESE, Working Paper. http://www.ebcenter.org.

Strang, D., \& Soule, S. (1998). Diffusion in organizations and social movements: From hybrid corn to poison pills. Annual Review of Sociology, 24, 265-290.

Tapscott, D. (1998). Growing up digital: The rise of the Net generation. New York: McGraw-Hill.

Valente, T. W. (1996). Social network thresholds in the diffusion of innovations. Social Networks, 18, 69-89.

Valente, T. W. (2005). Network models and methods for studying the diffusion of innovations. In: P. J Carrington, J. Scott \& S. Wasserman (Eds.), Models and methods in social network analysis. New York: Cambridge University Press.

Wejnert, B. (2002). Integrating models of diffusion of innovations: A conceptual framework. Annual Review of Sociology, 28, 297-326.

Wilkening, E. A. (1956). Roles of communicating agents in technological change in agriculture. Social Forces, 34, 361-367. 